\title{
Effects of cigarette smoke extract on human airway smooth muscle cells in COPD
}

\author{
Ling Chen ${ }^{1,2}$, Qi Ge ${ }^{2,3}$, Gavin Tjin ${ }^{2,4}$, Hatem Alkhouri ${ }^{5}$, Linghong Deng ${ }^{1,6}$, \\ Corry-Anke Brandsma ${ }^{7}$, lan Adcock ${ }^{8}$, Wim Timens ${ }^{7}$, Dirkje Postma ${ }^{9}$, \\ Janette K. Burgess ${ }^{2,3,4}$, Judith L. Black ${ }^{2,3}$ and Brian G.G. Oliver ${ }^{2,10}$
}

Affiliations: ${ }^{1}$ Key Laboratory of Biorheological Science and Technology, Ministry of Education, Bioengineering College, Chongqing University, Shapingba, Chongqing, China. ${ }^{2}$ Woolcock Institute of Medical Research, The University of Sydney, Sydney, NSW, Australia. ${ }^{3}$ Discipline of Pharmacology, The University of Sydney, Sydney, NSW, Australia. ${ }^{4}$ Central Clinical School, The University of Sydney, Sydney, NSW, Australia. ${ }^{5}$ Respiratory Research Group, Faculty of Pharmacy, The University of Sydney, Sydney, NSW, Australia. 'Institute of Biomedical Engineering and Health Science, Changzhou University, Changzhou, Jiangsu, China. ${ }^{7}$ Dept of Pathology and Medical Biology, University of Groningen, University Medical Center Groningen, Groningen, The Netherlands. ${ }^{8}$ Thoracic Medicine, Imperial College London, National Heart and Lung Institute, London, UK. ${ }^{9}$ Dept of Pulmonology, University of Groningen, University Medical Center Groningen, Groningen, The Netherlands. ${ }^{10}$ School of Medical and Molecular Biosciences, University of Technology Sydney, Sydney, NSW, Australia.

Correspondence: Brian G.G. Oliver, School of Medical and Molecular Biosciences, University of Technology Sydney, City campus, 15 Broadway, Ultimo NSW 2007, Australia. E-mail: brian.oliverduts.edu.au

ABSTRACT We hypothesised that the response to cigarette smoke in airway smooth muscle (ASM) cells from smokers with chronic obstructive pulmonary disease (COPD) would be intrinsically different from smokers without COPD, producing greater pro-inflammatory mediators and factors relating to airway remodelling.

ASM cells were obtained from smokers with or without COPD, and then stimulated with cigarette smoke extract (CSE) or transforming growth factor- $\beta 1$. The production of chemokines and matrix metalloproteinases (MMPs) were measured by ELISA, and the deposition of collagens by extracellular matrix ELISA. The effects of CSE on cell attachment and wound healing were measured by toluidine blue attachment and cell tracker green wound healing assays.

CSE increased the release of CXCL8 and CXCL1 from human ASM cells, and cells from smokers with COPD produced more CSE-induced CXCL1. The production of MMP-1, -3 and -10, and the deposition of collagen VIII alpha 1 (COL8A1) were increased by CSE, especially in the COPD group which had higher production of MMP-1 and deposition of COL8A1. CSE decreased ASM cell attachment and wound healing in the COPD group only.

ASM cells from smokers with COPD were more sensitive to CSE stimulation, which may explain, in part, why some smokers develop COPD.

@ERSpublications

Cigarette smoke extract induces airway remodelling-associated changes in airway smooth muscle cells in COPD patients http://ow.ly/wK0ey

This article has supplementary material available from erj.ersjournals.com

Received: Oct 012013 | Accepted after revision: May 042014 | First published online: June 252014

Conflict of interest: Disclosures can be found alongside the online version of this article at erj.ersjournals.com

Copyright @ERS 2014 


\section{Introduction}

Chronic obstructive pulmonary disease (COPD) is a leading cause of morbidity and mortality worldwide and results in an economic and social burden that is both substantial and increasing $[1,2]$. In COPD a number of changes occur in the lungs, namely the development of persistent inflammation and irreversible airflow limitation [3].

Airflow limitation is caused by three interrelated processes: thickening (remodelling) of the small airway walls, loss of small airways, and emphysema. However, small airway remodelling is considered to have the greatest influence on airflow limitation [4-6]. Furthermore, it is likely that the small airway remodelling is the primary pathological insult in COPD. In a study using micro-computed tomography analysis of COPD lung tissue, it was found that remodelling and loss of terminal bronchioles preceded emphysematous changes microscopically [7]. The small airway remodelling in COPD consists of folded mucosa, thickening of basement membrane and deposition of connective tissue, as well as increased airway smooth muscle (ASM) mass, especially in severe COPD $[6,8,9]$. The connective tissue consists of an intertwined framework of extracellular matrix (ECM) proteins, and the specific ECM proteins are known to be altered in the airways of patients with COPD $[10,11]$.

In the developed world, the main risk factor for the development of COPD is cigarette smoking. Through the use of both in vivo and in vitro models the effects of smoking on the aetiology of COPD is beginning to be understood. Most studies address the paradigm that the aetiology of COPD is cigarette smoke-induced inflammation leading to tissue damage; however, previous research suggested that airway remodelling may be induced independently of inflammation [12]. It has previously been found that fibroblasts from patients with COPD produced an excessive amount of fibronectin and perlecan or reduced proteoglycans (decorin and biglycan) in response to cigarette smoke extract (CSE), in comparison to cells from people without COPD $[12,13]$. Epithelial cells in COPD also respond differently to CSE [14], but whether COPD ASM cells respond differently to CSE is not known.

In this study we hypothesised that the response to cigarette smoke in ASM cells from people with COPD would be intrinsically different to that in ASM cells from people without COPD, specifically in the production of pro-inflammatory mediators and factors relating to airway remodelling.

\section{Material and methods \\ Study subjects}

Subject information was obtained regarding diagnosis, smoking history and lung function. Subjects with a diagnosis of asthma, infectious diseases or interstitial lung disease were not included. Samples were obtained from subjects who were classified as follows according to severity of airflow limitation [15]. 1) Non-COPD: $\mathrm{n}=21$, forced expiratory volume in $1 \mathrm{~s}(\mathrm{FEV} 1) /$ forced vital capacity (FVC) $\geqslant 70 \%$ and FEV1 $\geqslant 80 \%$. 2) COPD: $\mathrm{n}=20, \mathrm{FEV} 1 / \mathrm{FVC}<70 \%$. Full details are provided in the supplementary material (table S1). All study subjects or their next of kin provided written informed consent. Approval of all the experiments using human lung tissues was provided by the Ethics Review Committee of the South West Sydney Area Health Service, St Vincent's Hospital Sydney, and the University of Sydney Human Research Ethics Committee (all Sydney, Australia).

\section{Cell culture and sample preparation}

Human ASM cells were obtained from human lung by a method modified from one described previously [16]. Human ASM cells were microdissected from approximately sixth-order or greater bronchi, and were initially cultured in growth medium comprised of DMEM (Invitrogen, Carlsbad, CA, USA) supplemented with 5\% fetal bovine serum (DKSH, Melbourne, Australia), 1\% antibiotics (Invitrogen) and $25 \mathrm{mM}$ Hepes (Invitrogen). All the cells tested negative for the presence of mycoplasma before they were set up for experiments, and were used between passages 2 and 7. ASM cells were seeded in six-well or 96-well culture plates (BD Biosciences, North Ryde, Australia) at a density of $1 \times 10^{4} \mathrm{cells} \cdot \mathrm{cm}^{-2}$ in growth medium and incubated at $37^{\circ} \mathrm{C} / 5 \% \mathrm{CO}_{2}$ for $72 \mathrm{~h}$. Cells were starved in quiescing medium consisting of DMEM supplemented with $0.1 \%$ fetal bovine serum, $1 \%$ antibiotics and $25 \mathrm{mM}$ Hepes for $24 \mathrm{~h}$ before stimulation with CSE or $10 \mathrm{ng} \cdot \mathrm{mL}^{-1}$ of transforming growth factor (TGF)- $\beta 1$ (R\&D Systems, Minneapolis, MN, USA) in quiescing medium. After stimulation, supernatants from human ASM cells (in six-well plates) were collected, and cells (in 96-well plates) were lysed with $0.016 \mathrm{mM}$ ammonium hydroxide $\left(\mathrm{NH}_{4} \mathrm{OH}\right)$ at $37^{\circ} \mathrm{C}$ for $20 \mathrm{~min}$ then washed with $0.05 \%$ PBS-Tween $(\mathrm{Tw}) 20$ ( $\mathrm{vol} / \mathrm{vol})$. These supernatants and cell-free ECM plates were stored at $-20^{\circ} \mathrm{C}$ until analysis.

\section{Cigarette smoke extract}

We used Marlboro Red cigarettes (Philip Morris, Victoria, Australia), and each cigarette contained $1.1 \mathrm{mg}$ of nicotine, $15 \mathrm{mg}$ of tar, and $15 \mathrm{mg}$ of carbon monoxide. CSE was prepared by a method modified from 
one described previously [12]. Briefly, one Marlboro cigarette was bubbled through $25 \mathrm{~mL}$ of DMEM at a constant rate and this solution was regarded as 100\% concentration CSE. The 100\% CSE was freshly generated for each experiment, and diluted to final working concentration and used within $30 \mathrm{~min}$.

\section{Cell viability and toxicity assays}

Human ASM cells were seeded in 96-well plates as described previously, and cells were stimulated with serial dilutions of CSE from $0.05 \%$ to $50 \%$. The mitochondrial activity of living cells was tested by Thaizolyl blue tetrazolium bromide (MTT) (Sigma Aldrich, St Louis, MO, USA) assay. The membrane integrity of cells was tested by a lactate dehydrogenase (LDH) (Sigma Aldrich) assay, based on the amount of cytoplasmic LDH released into the medium. After stimulation for $72 \mathrm{~h}$, MTT and LDH release were measured using a spectrophotometer (Spectramax M2; Molecular Devices, Sunnyvale, CA, USA) setting with absorbance $570 \mathrm{~nm} / 690 \mathrm{~nm}$ and $490 \mathrm{~nm} / 690 \mathrm{~nm}$, respectively.

\section{Chemokine ELISA}

Human ASM cells were seeded in six-well plates as described previously, and cells were stimulated with different concentration of CSE or $10 \mathrm{ng} \cdot \mathrm{mL}^{-1}$ of TGF- $\beta 1$ for $72 \mathrm{~h}$. The concentrations of CXCL8 (interleukin (IL)-8), CXCL1 (GRO $\alpha$ ), CCL2, CCL5 and CXCL10 in the supernatants from human ASM cells were measured by using commercial human CXCL8/IL-8, CXCL1/GRO $\alpha$, CCL2/monocyte chemotactic protein-1, CCL5/RANTES, and CXCL10/inducible protein-10 ELISA kits (R\&D Systems) according to the manufacturer's instructions. The absorbance was read at $450 \mathrm{~nm} / 570 \mathrm{~nm}$ using a spectrophotometer (Spectramax M2).

\section{Transcription factor nuclear factor- $\kappa$ B and activator protein-1 activity assay}

Human ASM cells were seeded in six-well plates as described previously, and cells were stimulated with CSE $\left(5 \%\right.$ and $10 \%$ ) or $10 \mathrm{ng} \cdot \mathrm{mL}^{-1}$ of TGF- $\beta 1$ for $60 \mathrm{~min}$ and then nuclear extracts were collected. The activities of nuclear factor (NF) $-\kappa B$ and activator protein (AP)-1 of each sample were assessed using the TransAM ELISA kits (Active Motif, Carlsbad, CA, USA) according to the manufacturer's instructions. The absorbance was read at $450 \mathrm{~nm} / 655 \mathrm{~nm}$ using a spectrophotometer (Spectramax M2).

\section{Real-time PCR array}

Human ASM cells obtained from smokers with $(n=3)$ and without COPD $(n=3)$ were stimulated in vitro with $5 \% \mathrm{CSE}, 10 \% \mathrm{CSE}$ or $10 \mathrm{ng} \cdot \mathrm{mL}^{-1}$ of TGF- $\beta 1$. RNA was collected at $48 \mathrm{~h}$ then purified using the Isolate RNA mini kit (Bioline, London, UK), and mRNA was converted to cDNA using M-MLV reverse transcriptase (Invitrogen). Equal amounts of cDNA of each sample from the same group were pooled; the gene expression was then tested using TaqMan array human extracellular matrix and adhesion molecules 96-well plates according to the manufacturer's instructions (Invitrogen). Real-time PCR was performed using the StepOne Plus detection system and data were collected and analysed by StepOne software (Applied Biosystems, Melbourne, Australia). The relative abundance of mRNA was calculated using the $\Delta \Delta \mathrm{Ct}$ method [17], and results were normalised to $18 \mathrm{~S}$ rRNA.

\section{Matrix metalloproteinase ELISA}

Human ASM cells were seeded in six-well plates as described previously, and cells were stimulated with different concentration of CSE or $10 \mathrm{ng} \cdot \mathrm{mL}^{-1}$ of TGF- $\beta 1$ for $72 \mathrm{~h}$. The concentrations of total matrix metalloproteinase (MMP)-1, -2, $-3,-10$ and -12 were measured using human MMP ELISA kits (R\&D Systems) according to the manufacturer's instructions, and the reading was performed using a Luminex analyser (Luminex 200 System; Luminex, Brisbane, Australia). MMP-1 enzyme activity was measured using human active MMP-1 fluorescent assay kit (R\&D Systems), and the relative fluorescence units were determined using a fluorescence plate reader (Spectramax M2) setting with excitation wavelength $320 \mathrm{~nm}$ and emission wavelength $405 \mathrm{~nm}$.

\section{ECM ELISA}

Human ASM cells were seeded in 96-well plates as described previously, and cells were stimulated with different concentrations of CSE or $10 \mathrm{ng} \cdot \mathrm{mL}^{-1}$ of TGF- $\beta 1$ for $72 \mathrm{~h}$. Cell-free ECM plates were used to measure the deposition of protein in the ECM by ELISA according to the previously modified method [16]. Primary antibodies used for detecting ECM proteins were rabbit polyclonal anti-human COL5 antibody $\left(2 \mu \mathrm{g} \cdot \mathrm{mL}^{-1}\right)$ (Abcam, Cambridge, UK), rabbit polyclonal anti-human collagen VIII alpha 1 (COL8A1) antibody $\left(2 \mu \mathrm{g} \cdot \mathrm{mL}^{-1}\right)$ (Novus Biologicals, Littleton, CO, USA), mouse monoclonal anti-human fibronectin antibody $\left(2 \mu \mathrm{g} \cdot \mathrm{mL}^{-1}\right)$ (Millipore, Billerica, MA, USA), and mouse monoclonal anti-human perlecan antibody $\left(2 \mu \mathrm{g} \cdot \mathrm{mL}^{-1}\right)$ (Invitrogen). Rabbit IgG (Dako Cytomation, Glostrup, CA, USA) isotype control antibody and mouse IgG1 $\kappa$ isotype control antibody (BD Biosciences) were used at the same concentration as the primary 
antibodies. For measurement of COL8A1 and perlecan, the biotinylated goat anti-rabbit antibody $0.5 \mu \mathrm{g} \cdot \mathrm{mL}^{-1}$ and biotinylated chicken anti-mouse antibody $0.8 \mu \mathrm{g} \cdot \mathrm{mL}^{-1}$ were used, respectively.

\section{Western blots}

Human ASM cells were seeded in six-well plates as described previously, and cells were stimulated with CSE ( $5 \%$ or $10 \%$ ) or TGF- $\beta 1$ for $72 \mathrm{~h}$. The supernatants from each sample were collected to assess the soluble COL1 and soluble fibronectin using Western blots. Proteins were size fractionated on $10 \%$ polyacrylamide gels, transferred to polyvinylidene fluoride membranes and blocked in 5\% (wt/vol) skim milk solution for $1 \mathrm{~h}$. The membranes were incubated with primary antibody $\left(8.8 \mu \mathrm{g} \cdot \mathrm{mL}^{-1}\right.$ of mouse monoclonal anti-COL1 antibody (Sigma Aldrich) or $1 \mu \mathrm{g} \cdot \mathrm{mL}^{-1}$ of mouse monoclonal anti-human fibronectin antibody (Millipore) in $2 \%$ bovine serum albumin/TBS-Tw) for $2 \mathrm{~h}$, followed by incubation with secondary antibody $\left(2.6 \mu \mathrm{g} \cdot \mathrm{mL}^{-1}\right.$ of rabbit anti-mouse Ig-horseradish peroxidase antibody (Dako Cytomation) in 2\% bovine serum albumin/TBS-Tw) for $1 \mathrm{~h}$. Immunoblot detection was performed using Immobilon Western Chemluminescent HRP Subtrate (Millipore) and bands were analysed using Kodak image station 4000 MM (Eastman Kodak Co., New York, NY, USA). The amount of protein present in each sample was determined as the densitometric density.

\section{Immunohistochemistry}

The preparation of immunohistochemical samples and immunohistochemical methods have been described previously [18]. The airway sections were treated to minimise nonspecific background staining, and incubated with primary rabbit polyclonal anti-human COL8A1 antibody $1 \mu \mathrm{g} \cdot \mathrm{mL}^{-1}$ (Abcam) and rabbit IgG isotype control antibody $1 \mu \mathrm{g} \cdot \mathrm{mL}^{-1}$ (Dako Cytomation). The conjugated secondary antibody was labelled polymer anti-rabbit (EnVision+System-HRP; Dako Cytomation) and the tissue staining was visualised with substrate chromogen, liquid DAB (Dako Cytomation). 10 images of each section (one section per subject) were taken and immunostaining was quantified using Fiji software (ImageJ) [19]. Full details are provided in the supplementary material.

\section{Cell attachment assay}

96-well culture plates were exposed to growth medium for $72 \mathrm{~h}$ and to quiescing medium for $24 \mathrm{~h}$ then exposed to quiescing medium with different concentration of CSE $(0.05 \%$ to $10 \%)$ for $72 \mathrm{~h}$. Human ASM cells were seeded on these treated plates at a density of $5 \times 10^{4}$ cells $\cdot \mathrm{cm}^{-2}$ in quiescing medium for $2 \mathrm{~h}$. Cell attachment was detected by a toluidine blue attachment assay as previously described [20]. The relative number of attached cells was measured using spectrophotometry at an absorbance of $595 \mathrm{~nm}$ (Spectramax M2). Full details are provided in the supplementary material.

\section{Wound healing assay}

An Oris cell migration assembly kit (Platypus Technologies, Madison, WI, USA) was used to perform the wound healing assay. The wound was created on the treated 96-well black plate and cells were labelled with cell tracker green CMFDA (Invitrogen). The labelled human ASM cells were seeded on the wounded black plate at a density of $5 \times 10^{4}$ cells $\cdot \mathrm{cm}^{-2}$ in growth medium. After adhesion for $24 \mathrm{~h}$ the stoppers were removed, and incubation was continued for $4 \mathrm{~h}$. The wound healing value was measured using a fluorescence plate reader (Wallac VICTOR ${ }^{2}$; Perkin Elmer, Waltham, MA, USA) read from the bottom with excitation wavelength set at $485 \mathrm{~nm}$ and emission wavelength at $535 \mathrm{~nm}$. Full details are provided in the supplementary material.

\section{Statistical analysis}

Data analysis was performed using GraphPad Prism 5.0 software (GraphPad Software, San Diego, CA, USA). All the data are presented as mean \pm SEM. One-way ANOVA, two-way ANOVA plus Bonferroni posttest or Mann-Whitney test were used as appropriate to determine the statistical significance. A p-value $\leqslant 0.05$ was considered significant.

\section{Results}

\section{Cytotoxicity of CSE on ASM cells}

As high concentrations of CSE are known to be cytotoxic we used two toxicology assays, assessment of mitochondrial activity via MTT and membrane integrity via $\mathrm{LDH}$ release, in order to ensure that the concentrations of CSE we used had no toxic effects on human ASM cells. CSE at a concentration $\geqslant 15 \%$ substantially reduced viability (fig. 1); therefore, we used $0.05 \%$ to $10 \%$ CSE as stimulation in subsequent experiments. 

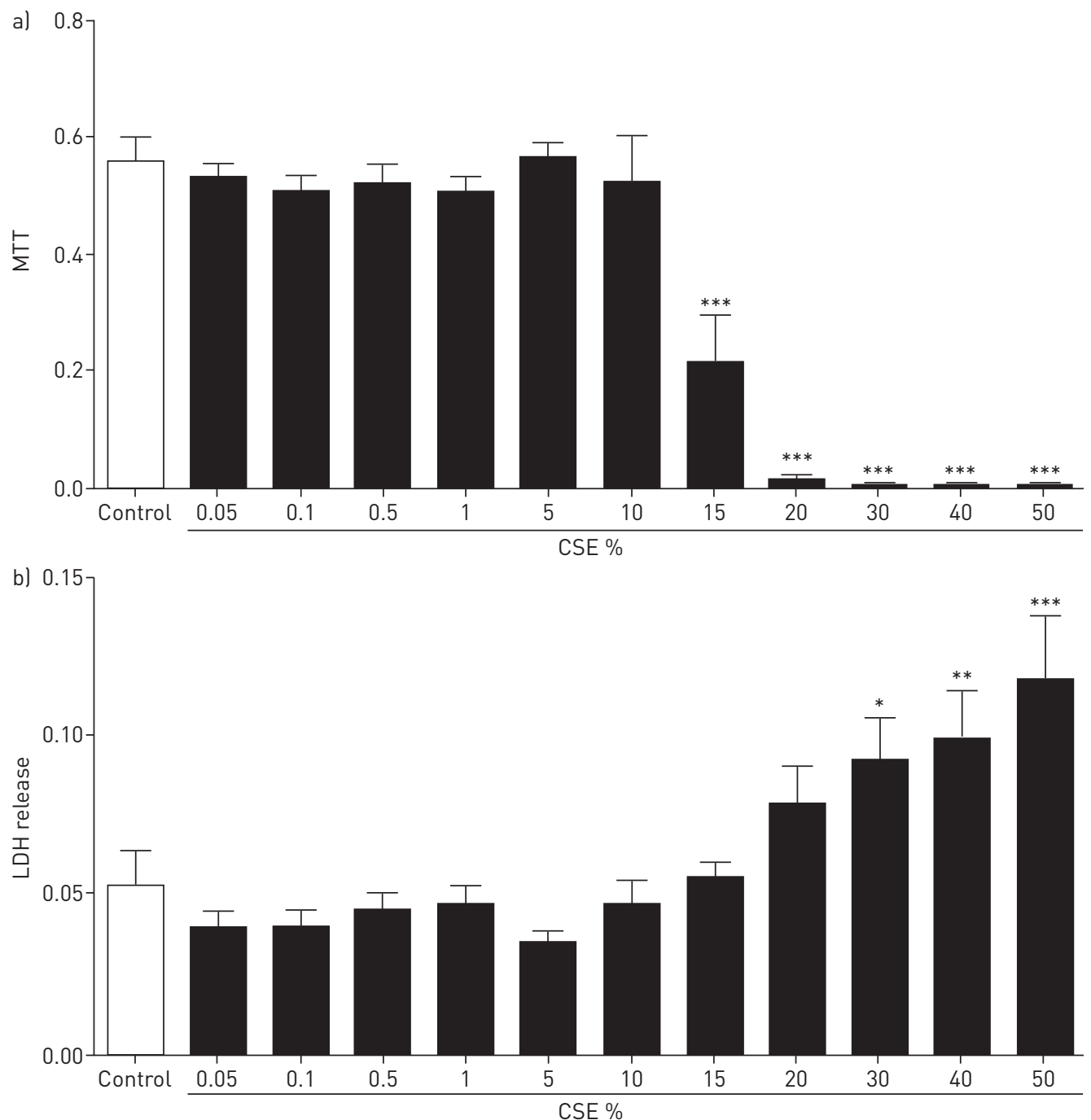

FIGURE 1 The effect of cigarette smoke extract (CSE) on cell viability. The cytotoxicity of CSE on a) the mitochondrial activity and b) lactate dehydrogenase (LDH) release of human airway smooth muscle (ASM) cells was measured by Thaizolyl blue tetrazolium bromide (MTT) and LDH assays at an absorbance of $570 \mathrm{~nm} / 690 \mathrm{~nm}$ and $490 \mathrm{~nm} / 690 \mathrm{~nm}$, respectively. Human ASM cells were stimulated with serial dilution of CSE for $72 \mathrm{~h}(n=4)$. Data are presented as mean \pm SEM. One-way ANOVA plus Bonferroni post-test was used to determine statistical significance. ${ }^{*}: \mathrm{p}<0.05$; ${ }^{* *}: \mathrm{p}<0.01 ;{ }^{* *}: \mathrm{p}<0.001$, compared with control.

\section{CSE induces chemokines}

As CSE is known to induce CXCL8 release from human ASM cells [21], we used this output to validate our in vitro model. CXCL8 release was increased by $10 \% \mathrm{CSE}$ and $10 \mathrm{ng} \cdot \mathrm{mL}^{-1}$ of TGF- $\beta 1$ in both non-COPD and COPD groups (fig. $2 \mathrm{a}$ and b). The release of CXCL1 was increased by $10 \%$ CSE in the non-COPD group and increased by both $5 \%$ and $10 \%$ CSE in the COPD group; however, TGF- $\beta 1$ did not induce the release of CXCL1 in either group (fig. $2 \mathrm{c}$ and $\mathrm{d}$ ). There were no differences in basal or maximum production of CXCL8 and CXCL1 between ASM cells from these two groups. Our results show that the release of CCL5 and CXCL10 from ASM cells were too low to be detected (the detection limit of these assays are $15.625 \mathrm{pg} \cdot \mathrm{mL}^{-1}$ and $31.35 \mathrm{pg} \cdot \mathrm{mL}^{-1}$, respectively). We found that CCL2 was produced by ASM cells, but this was not induced by CSE or TGF- $\beta 1$, and there were no differences between the non-COPD and COPD groups (data not shown).

\section{CSE effects transcription factors DNA binding activity}

Our results show that neither CSE nor TGF- $\beta 1$ increased the activity of transcription factor NF- $\kappa B$ (fig. S1a and b); however, 5\% CSE increased the activity of transcription factor AP-1 in only the non-COPD group (fig. S1c and d). 

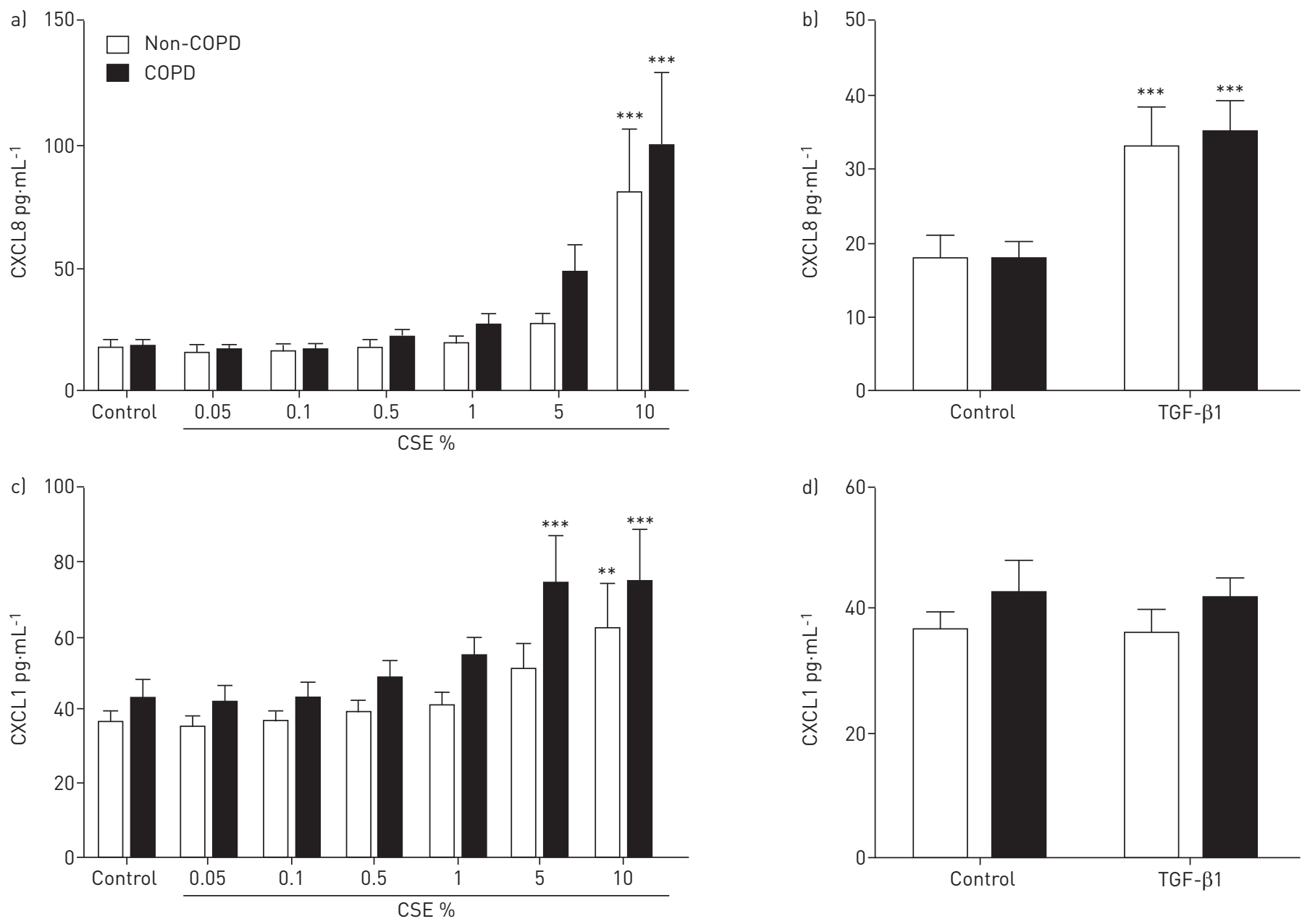

FIGURE 2 Release of CXCL8 and CXCL1 from human airway smooth muscle (ASM) cells. The concentrations of a, b) CXCL8 and c, d) CXCL1 in supernatant from human ASM cells from subjects with $(n=9)$ and without $(n=9)$ chronic obstructive pulmonary disease (COPD) after $72 \mathrm{~h}$ stimulation with cigarette smoke extract (CSE) or transforming growth factor (TGF)- $\beta 1$ were measured by ELISA. Data are presented as mean \pm SEM. Two-way ANOVA plus Bonferroni post-test was used to determine statistical significance. ${ }^{* *}: \mathrm{p}<0.01,{ }^{* *}: \mathrm{p}<0.001$, compared with control.

\section{Gene expression of ECM and adhesion molecule-related genes}

To investigate the potential effects of CSE on airway remodelling we used a PCR-based array as a screening tool. The gene expression of 70 ECM proteins, adhesion molecules and MMPs were assessed in response to CSE and TGF- $\beta 1$ stimulations (fig. S2). CSE upregulated more ECM- and adhesion molecule-associated genes than TGF- $\beta 1$, and there were differences in MMPs gene expression between CSE and TGF- $\beta 1$ stimulations. Using a $\geqslant 2$ cut-off line and/or $>1.5$ fold differences between COPD and non-COPD group, MMP-1, -2, -3, -10 and -12, and COL5, COL7 and COL8A1 were further investigated.

\section{CSE induces MMPs}

To verify the MMP changes, we measured the release of MMP-1, -2, -3, -10 and -12 from human ASM cells. After stimulation with either CSE or TGF- $\beta 1$, the concentration of total MMP-12 in the supernatants from human ASM cells was too low to be detected (data not shown). The concentration of total MMP-1 was increased by $10 \%$ CSE in the non-COPD group and increased by $5 \%$ and $10 \%$ CSE in the COPD group (fig. $3 \mathrm{a}$ and $\mathrm{b}$ ). Neither CSE nor TGF- $\beta 1$ affected the production of MMP-2 (fig. $3 \mathrm{c}$ and $\mathrm{d}$ ). $10 \%$ CSE increased the release of MMP-3 and MMP-10 in both groups, whilst TGF- $\beta 1$ increased the release of MMP-3 and MMP-10 in the COPD group only (fig. $3 \mathrm{e}-\mathrm{h}$ ).

\section{The production of active MMP-1}

To further investigate the effect of CSE on the activity of MMP-1, we measured the active form of MMP-1 from human ASM cells. The concentration of active MMP-1 was increased by $10 \%$ CSE in both groups, while TGF- $\beta 1$ decreased the release of active MMP-1 in the non-COPD group only (fig. 4). 

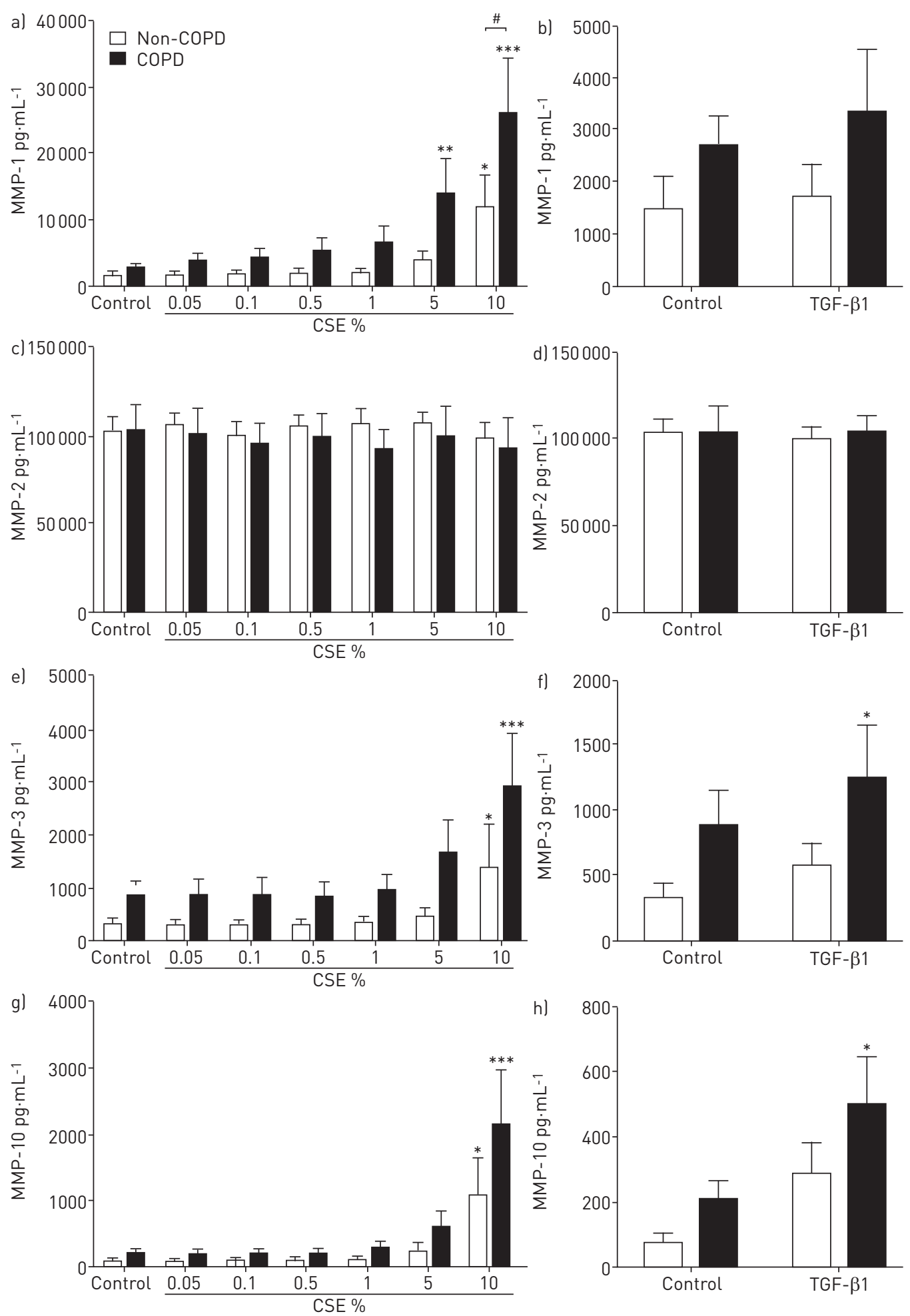

FIGURE 3 Production of matrix metalloproteinases (MMPs) from human airway smooth muscle (ASM) cells. The concentrations of a ,b) MMP-1, c, d) MMP-2, e, f) MMP-3, and g, h) MMP-10 in supernatant from human ASM cells from subjects with $(n=8)$ and without $(n=7)$ chronic obstructive pulmonary disease (COPD) after $72 \mathrm{~h}$ stimulation with cigarette smoke extract (CSE) or transforming growth factor (TGF- $\beta 1$ ) were measured by ELISA. Data are presented as mean \pm SEM. Two-way ANOVA plus Bonferroni post-test was used to determine statistical significance. ${ }^{*}: \mathrm{p}<0.05$; ${ }^{* *}: \mathrm{p}<0.01 ;{ }^{* * *}: \mathrm{p}<0.001$, compared with control. ${ }^{\#}: \mathrm{p}<0.05$, comparison between two groups. 

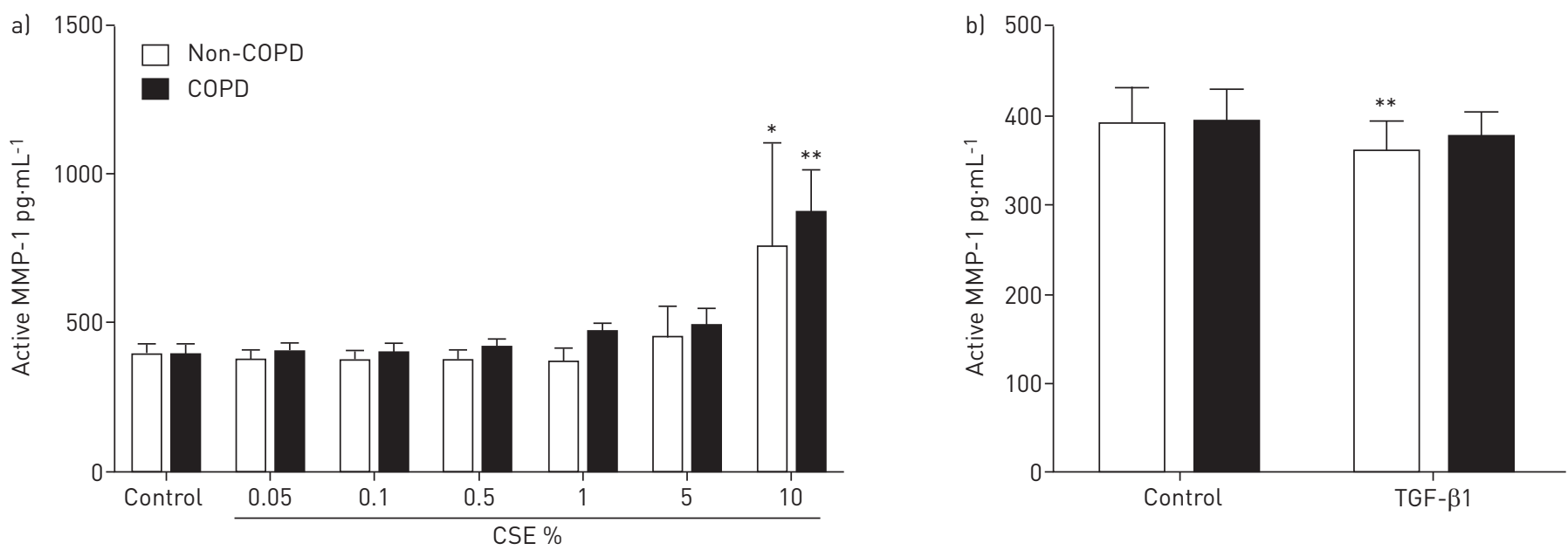

FIGURE 4 Production of active matrix metalloproteinase (MMP)-1 from human airway smooth muscle (ASM) cells. The concentrations of active MMP-1 in the supernatants from human ASM cells from subjects with $(n=5)$ and without $(n=5)$ chronic obstructive pulmonary disease (COPD) after 72 h stimulation with cigarette smoke extract (CSE) or transforming growth factor (TGF)- $\beta 1$ were measured by ELISA. Data are presented as mean \pm SEM. Two-way ANOVA plus Bonferroni post-test was used to determine statistical significance. ${ }^{*}: \mathrm{p}<0.05 ;{ }^{\star *}: \mathrm{p}<0.01$, compared with control.

\section{The deposition of ECM proteins}

To verify the alteration of ECM proteins after stimulation with CSE or TGF- $\beta 1$, we assessed the deposition of COL5, COL7 and COL8A1 in the ECM. The deposition of COL7 was too low to be detected (data not shown). CSE did not alter the deposition of COL5 (fig. S3). The deposition of COL8A1 was increased by $0.5 \%, 1 \%, 5 \%$ and $10 \%$ CSE only in the COPD group, and there was significantly more COL $8 \mathrm{~A} 1$ induced by $1 \%$ and $5 \%$ CSE from the COPD cells compared to the non-COPD cells (fig. $5 a$ ). TGF- $\beta 1$ increased the deposition of COL8A1 in the COPD group only (fig. 5b). CSE did not alter the deposition of fibronectin from either group which is in stark contrast to previous findings in fibroblasts [12], and CSE inhibited the deposition of perlecan in human ASM cells from both groups (fig. S4).

\section{The release of ECM proteins}

To verify the alteration of soluble ECM proteins after stimulation with CSE or TGF- $\beta 1$, we assessed the soluble COL1 and soluble fibronectin in the supernatants using Western blots. Our results showed that neither CSE nor TGF- $\beta 1$ significantly increased the release of COL1 (fig. S5). Our results also showed that CSE did not induce the release of soluble fibronectin; however, TGF- $\beta 1$ significantly increased the release of fibronectin (fig. S6).
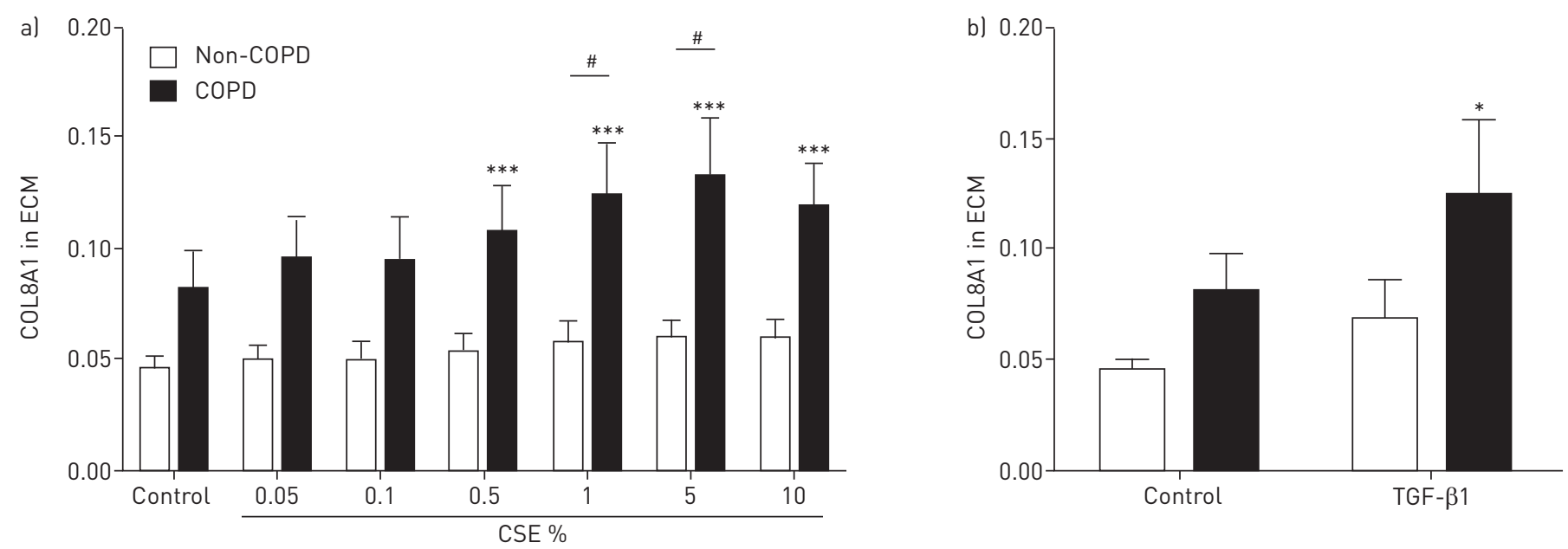

FIGURE 5 The deposition of collagen VIII alpha 1 (COL8A1) from human airway smooth muscle (ASM) cells. The deposited COL8A1 in the extracellular matrix $(\mathrm{ECM})$ from human ASM cells from subjects with $(\mathrm{n}=7)$ and without $(\mathrm{n}=7)$ chronic obstructive pulmonary disease $(\mathrm{COPD})$ after $72 \mathrm{~h}$ stimulation with cigarette smoke extract (CSE) or transforming growth factor (TGF)- $\beta 1$ was measured by ECM ELISA at an absorbance of $450 \mathrm{~nm} / 570 \mathrm{~nm}$. Data are presented as

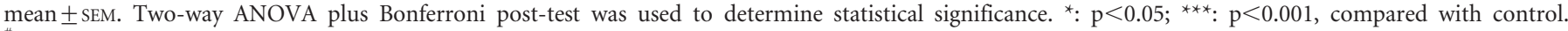
${ }^{\#}: \mathrm{p}<0.05$, comparison between two groups. 


\section{COL8A1 in airway bronchus}

As we found greater CSE-induced COL8A1 by the COPD ASM cells, we next investigated if our in vitro findings were reflective of COPD in vivo. Immunohistochemistry revealed COL8A1 was expressed in airway tissue from patients with $(n=10)$ and without COPD $(n=7)$. In the airways from both groups the COL8A1 appeared to be localised in the basement membranes, vascular walls and ASM bundles. The positive staining was controlled by threshold and isotype control staining. Using densitometric analysis (quantification of staining area) we found there was higher overall expression of COL8A1 in the COPD group (fig. 6).

\section{CSE inhibits cell attachment and wound healing}

To further investigate the effect of CSE on the function of human ASM cells, we assessed cell attachment of ASM cells from people with $(n=5)$ and without $(n=5)$ COPD. CSE significantly decreased the attachment
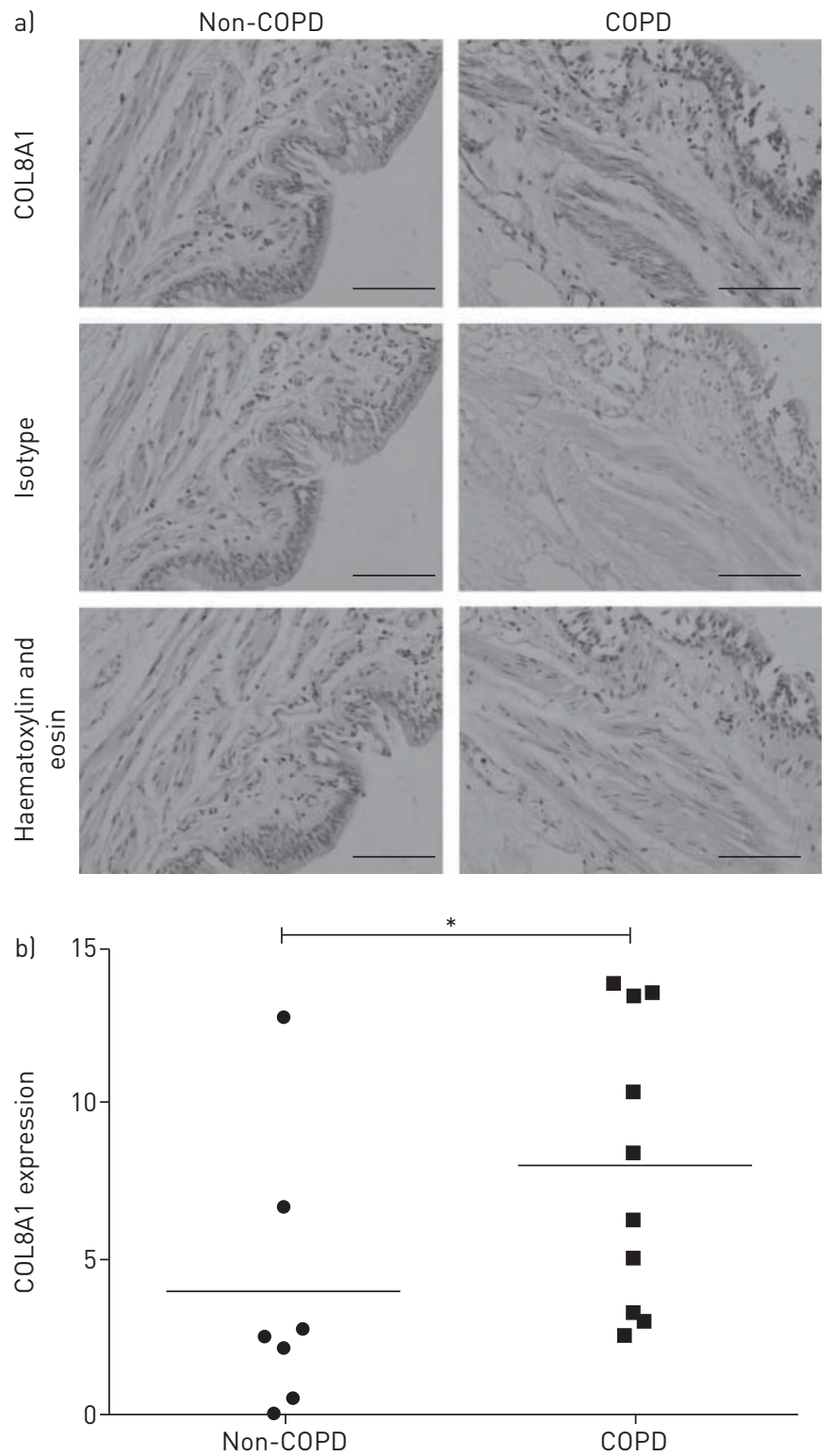

FIGURE 6 Collagen VIII alpha 1 (COL8A1) airway tissue staining. a) COL8A1 in airway bronchus from subjects with $(n=10)$ and without $(n=7)$ chronic obstructive pulmonary disease (COPD) was measured by immunohistochemistry. Specific staining was detected using a chemical chromophore, DAB (brown), and the cell nucleus was counterstained with haematoxylin (blue). Tissue structure was stained with haematoxylin and eosin. Scale bars $=100 \mu \mathrm{m}$. b) Immunostaining of COL8A1 in non-COPD and COPD groups were quantified by positive staining area and corrected with isotype control. Data are presented as median. The Mann-Whitney test was used to determine statistical significance. ${ }^{\star}: \mathrm{p}<0.05$. 


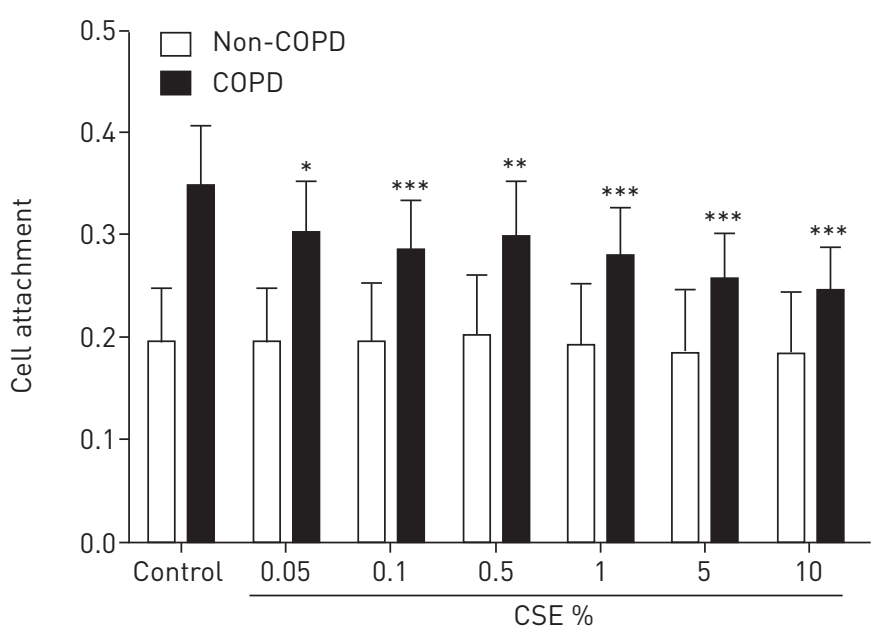

FIGURE 7 The effect of cigarette smoke extract (CSE) on 2-h cell attachment at an absorbance of $595 \mathrm{~nm}$. Cell attachment on a CSE treated plate of human airway smooth muscle cells from subjects with $(n=5)$ and without $(n=5)$ chronic obstructive pulmonary disease (COPD) were measured by toluidine blue assay. Data are presented as mean \pm SEM. Two-way ANOVA plus Bonferroni post-test was used to determine statistical significance. ${ }^{\star}: \mathrm{p}<0.05 ;{ }^{\star *}: \mathrm{p}<0.01$; $* * *: \mathrm{p}<0.001$, compared with control.

of ASM cells to culture plates from the COPD group only (fig. 7). Wound healing assays showed that high concentration of CSE significantly decreased the rate of wound healing in human ASM cells $(n=6)$ (fig. S7).

\section{Discussion}

We have found differential responses to CSE in ASM cells from smokers with and without COPD. Specifically MMP-1 and the deposition of COL8A1 in ASM cells were increased by CSE, and these increases were higher in the COPD group. Our results also showed that CSE decreased ASM cell attachment to culture plates and wound healing specifically in cells isolated from smokers with COPD. These findings suggest that ASM cells from smokers with COPD are more sensitive to CSE stimulation which may explain, in part, the development of COPD in some smokers.

COPD is an inflammatory disease characterised by an increased number of neutrophils [9, 22], and increased amount of neutrophil chemokines (such as CXCL8 and CXCL1) in bronchoalveolar lavage fluid $[23,24]$. CSE is a potent inducer of CXCL8 in ASM cells $[21,25]$; however, whether hypersecretion of CXCL8 occurs in ASM cells isolated from patients with COPD as in other airway cells was not known $[26,27]$. Therefore, we also measured CSE-induced CXCL8, and found CSE increased the release of CXCL8 from ASM cells yet without differences between cells from people with and without COPD. We also measured CSE-induced CXCL1 and found CSE increased the release of CXCL1 from ASM cells. Furthermore, ASM cells from COPD patients were more sensitive to CSE stimulation for the production of CXCL1. Both CXCL8 and CXCL1 have similar biological properties, in that they both have effects on the recruitment of neutrophils [28-30]. In our study we used ASM cells from smokers with and without COPD. The induction of CXCL8 and CXCL1 by CSE in ASM cells from both groups may reflect the observation that neutrophils are increased in COPD patients [31] and smokers without COPD [32]. Furthermore, as low concentrations of CSE induced CXCL1 in the COPD cells only, this suggested that these cells were hyperresponsive to CSE, and may explain why some smokers develop COPD and others do not.

Our results showed that high concentrations of CSE increased the release of both proMMP-1 and active MMP-1 (interstitial collagenase) from human ASM cells, and this seemed more pronounced in smokers with COPD than those without COPD. When we measured only active MMP-1 we found similar production between cells from both groups. This indicates that production of active MMP-1 in ASM may not be a key determinant of lung pathology in COPD, but may be related to processes common to both smokers with and without COPD. In other cells, CSE increased the production of MMP-1 from human epithelial cells and human lung fibroblasts which appear to be driven primarily through the extracellular regulated kinase-1/2 mitogen-activated protein kinase pathway [33,34]. We also found human ASM cells constitutively produced high levels of MMP-2 (gelatinase A) and this was not increased by CSE, which is in contrast to findings in cigarette smoke-exposed fibroblasts [35].

Compared to other MMPs, MMP-3 (stromelysin 1) and -10 (stromelysin 2) have not been extensively studied to date. Our study showed that CSE increases the gene expression of MMP-3 and -10 in human 
ASM cells, and that 10\% CSE increases production of MMP-3 and -10 . These results indicate that both MMP-3 and -10 may lead to different progression in smokers with COPD. Two genotyping studies indicated that MMP-3 polymorphisms associate with disease progression in COPD [36, 37]. Another study showed the expression of the MMP-10 gene was increased in both small airways and the parenchyma surrounding small airways in association with progression of COPD [38]. In addition, our results found MMP-12 (macrophage elastase) gene expression to be increased by CSE in vitro. However, the release of MMP-12 protein from CSE stimulated ASM was lower than the detection limit of the assay $\left(9.2 \mathrm{pg} \cdot \mathrm{mL}^{-1}\right)$.

It has previously been shown that CSE increased the deposition of fibronectin and perlecan from COPD fibroblasts [12], so in this study we also measured their production by ASM cells. However, CSE did not affect the production of fibronectin in COPD ASM cells, and decreased the production of perlecan indicating that responses to CSE are cell type specific. Our array data showed that several collagens also changed in response to CSE stimulation, so we chose to evaluate COL5, COL7 and COL8. The protein level of COL5 did not change in response to CSE, and the tools to measure COL7 were unreliable. However, CSE induced greater COL8 production from COPD than from control ASM cells. There is little known about COL8 in COPD, especially not on the amount of COL8 in airways of people with and without COPD. In this study we found that the expression of COL8 was increased in COPD airways, particularly in and around the smooth muscle bundles, suggesting that the smooth muscle produces COL8 in situ and indicating that the deposition of COL8 from smokers with COPD is likely to contribute to the airway pathology. COL8 has a short triple helix and contains $\alpha 1$ and $\alpha 2$ chains, and each $\alpha$ chain contains a collagenous domain, a short $\mathrm{N}$-terminal non-triple-helical region (NC2) and a longer C-terminal non-triple-helical domain (NC1). As is known for other collagens, different regions of COL8 can have opposing biological effects. For example, the entire COL8 molecule increased aortic smooth muscle cell proliferation and migration [39], whilst the NC1 domain of COL8A1 inhibited the mitochondrial activity of bovine aortic endothelial cells [40]. COL8 has not been reported previously as a determinant of ECM in COPD, but exposure of pregnant mice to pollution resulted in increased COL8 in the tubular cells in the kidney of offspring [41]. This raises the question as to whether similar hereditary effects could occur in the offspring of pregnant mothers who smoke. In addition, the functional and long-term outcomes of such exposures have not been examined.

We have not investigated if any interaction between MMP-1 and COL8 occurs, and have not been able to find specific examples in the literature. It would be tempting to speculate that the increased MMP could degrade the collagen; however, we found that they both increased at the same time, showing that the net effect is collagen deposition.

In COPD there is impaired repair in the small airway walls and alveolar walls [6,7]. Our results show that CSE only reduced cell attachment in human ASM cells from patients with COPD, and higher concentration of CSE also decreased the wound-healing rate of ASM cells. Those results may indicate an innate difference of ASM cells from smokers with and without COPD. One study about the effect of CSE on the function of the human lung has shown that CSE reduces the migration and contractile activity of normal human bronchial smooth muscle cells [42]. In another study it was shown that CSE impairs the wound healing of bovine bronchial epithelial cells via a reactive oxygen species dependent mechanism [43]. Another study has shown CSE inhibits the proliferation of human lung fibroblasts [44], but whether these fibroblasts were derived from patients with COPD or not was not clear.

To investigate if differences in transcription factor activity could account for the increased responsiveness of the COPD ASM cells to CSE we chose to measure the activity of the transcription factors NF- $\mathrm{KB}$ and AP-1, as these have previously been shown to be involved in the release of MMPs and cytokines from ASM cells $[45,46]$. We found no evidence of increased transcription factor activity in COPD ASM cells. This suggests that the increased response to cigarette smoke in the COPD cells may occur due to epigenetic changes, as we have found in other cells in COPD [47].

In conclusion, we showed the differential production of chemokines, MMPs and collagens by human ASM cells from people with and without COPD in response to cigarette smoke stimulation. ASM cells isolated from subjects with COPD showed a higher response to cigarette smoke in the release of inflammatory mediators and factors associated with airway remodelling and cell behaviour. Our data from this manuscript suggests that the ASM in COPD is capable of responding to the soluble components of cigarette smoke. This would act to recruit neutrophils (through the release of chemokines) and potentially affect other airway cells through the altered deposition of ECM. Since the amount of smooth muscle is positively correlated with COPD severity these effects may be amplified in severe COPD. Therefore, our findings suggest that ASM cells from smokers with COPD contribute to the pathological development of this disease. 


\section{Acknowledgements}

We would like to acknowledge the collaborative effort of the cardiopulmonary transplant team and the pathologists at St Vincent's Hospital (Sydney, Australia), and the thoracic physicians and pathologists at the Royal Prince Alfred Hospital (Sydney) and Strathfield Private Hospital (Strathfield, Australia).

\section{References}

1 Lopez AD, Shibuya K, Rao C, et al. Chronic obstructive pulmonary disease: current burden and future projections. Eur Respir J 2006; 27: 397-412.

2 Mathers CD, Loncar D. Projections of global mortality and burden of disease from 2002 to 2030. PLoS Med 2006; 3: e442.

3 Seymour ML, Gilby N, Bardin PG, et al. Rhinovirus infection increases 5-lipoxygenase and cyclooxygenase-2 in bronchial biopsy specimens from nonatopic subjects. J Infect Dis 2002; 185: 540-544.

4 Hogg JC, Macklem PT, Thurlbeck WM. Site and nature of airway obstruction in chronic obstructive lung disease. N Engl J Med 1968; 278: 1355-1360.

5 Van Brabandt H, Cauberghs M, Verbeken E, et al. Partitioning of pulmonary impedance in excised human and canine lungs. J Appl Physiol 1983; 55: 1733-1742.

6 Hogg JC, Chu F, Utokaparch S, et al. The nature of small-airway obstruction in chronic obstructive pulmonary disease. N Engl J Med 2004; 350: 2645-2653.

7 McDonough JE, Yuan R, Suzuki M, et al. Small-airway obstruction and emphysema in chronic obstructive pulmonary disease. $N$ Engl J Med 2011; 365: 1567-1575.

8 Bosken CH, Wiggs BR, Paré PD, et al. Small airway dimensions in smokers with obstruction to airflow. Am Rev Respir Dis 1990; 142: 563-570.

9 Pesci A, Majori M, Cuomo A, et al. Neutrophils infiltrating bronchial epithelium in chronic obstructive pulmonary disease. Respir Med 1998; 92: 863-870.

10 Kranenburg AR, Willems-Widyastuti A, Moori WJ, et al. Enhanced bronchial expression of extracellular matrix proteins in chronic obstructive pulmonary disease. Am J Clin Pathol 2006; 126: 725-735.

11 Annoni R, Lanças T, Yukimatsu Tanigawa R, et al. Extracellular matrix composition in COPD. Eur Respir J 2012; 40: 1362-1373.

12 Krimmer DI, Burgess JK, Wooi TK, et al. Matrix proteins from smoke-exposed fibroblasts are pro-proliferative. Am J Respir Cell Mol Biol 2012; 46: 34-39.

13 Brandsma CA, Timens W, Jonker MR, et al. Differential effects of fluticasone on extracellular matrix production by airway and parenchymal fibroblasts in severe COPD. Am J Physiol Lung Cell Mol Physiol 2013; 305: L582-L589.

14 Comer DM, Kidney JC, Ennis M, et al. Airway epithelial cell apoptosis and inflammation in COPD, smokers and nonsmokers. Eur Respir J 2013; 41: 1058-1067.

15 Corne JM, Marshall C, Smith S, et al. Frequency, severity, and duration of rhinovirus infections in asthmatic and non-asthmatic individuals: a longitudinal cohort study. Lancet 2002; 359: 831-834.

16 Chen L, Ge Q, Black JL, et al. Differential regulation of extracellular matrix and soluble fibulin-1 levels by TGF- $\beta 1$ in airway smooth muscle cells. PLoS One 2013; 8: e65544.

17 Livak KJ, Schmittgen TD. Analysis of relative gene expression data using real-time quantitative PCR and the $2(-\Delta \Delta$ CT method. Methods 2001; 25: 402-408.

18 Faiz A, Tjin G, Harkness L, et al. The expression and activity of cathepsins D, H and $\mathrm{K}$ in asthmatic airways. PLoS One 2013; 8: e57245.

19 Schindelin J, Arganda-Carreras I, Frise E, et al. Fiji: an open-source platform for biological-image analysis. Nat Methods 2012; 9: 676-682.

20 Moir LM, Black JL, Krymskaya VP. TSC2 modulates cell adhesion and migration via integrin- $\alpha 1 \beta 1$. Am J Physiol Lung Cell Mol Physiol 2012; 303: L703-L710.

21 Oltmanns U, Chung KF, Walters M, et al. Cigarette smoke induces IL-8, but inhibits eotaxin and RANTES release from airway smooth muscle. Respir Res 2005; 6: 74.

22 Di Stefano A, Capelli A, Lusuardi M, et al. Severity of airflow limitation is associated with severity of airway inflammation in smokers. Am J Respir Crit Care Med 1998; 158: 1277-1285.

23 Traves SL, Culpitt SV, Russell RE, et al. Increased levels of the chemokines GRO $\alpha$ and MCP-1 in sputum samples from patients with COPD. Thorax 2002; 57: 590-595.

24 Baines KJ, Simpson JL, Gibson PG. Innate immune responses are increased in chronic obstructive pulmonary disease. PLoS One 2011; 6: e18426.

25 Gosens R, Rieks D, Meurs H, et al. Muscarinic M3 receptor stimulation increases cigarette smoke-induced IL-8 secretion by human airway smooth muscle cells. Eur Respir J 2009; 34: 1436-1443.

26 Mio T, Romberger DJ, Thompson AB, et al. Cigarette smoke induces interleukin-8 release from human bronchial epithelial cells. Am J Respir Crit Care Med 1997; 155: 1770-1776.

27 Smith RS, Fedyk ER, Springer TA., et al. IL-8 production in human lung fibroblasts and epithelial cells activated by the Pseudomonas autoinducer N-3-oxododecanoyl homoserine lactone is transcriptionally regulated by NF-kappa B and activator protein-2. J Immunol 2001; 167: 366-374.

28 Das ST, Rajagopalan L, Guerrero-Plata A, et al. Monomeric and dimeric CXCL8 are both essential for in vivo neutrophil recruitment. PLoS One 2010; 5: e11754.

29 Zhang XW, Liu Q, Wang Y, et al. CXC chemokines, MIP-2 and KC, induce P-selectin-dependent neutrophil rolling and extravascular migration in vivo. Br J Pharmacol 2001; 133: 413-421.

30 Suratt BT, Petty JM, Young SK, et al. Role of the CXCR4/SDF-1 chemokine axis in circulating neutrophil homeostasis. Blood 2004; 104: 565-571.

31 Pilette C, Colinet B, Kiss R, et al. Increased galectin-3 expression and intra-epithelial neutrophils in small airways in severe COPD. Eur Respir J 2007; 29: 914-922.

32 Morrison D, Rahman I, Lannan S, et al. Epithelial permeability, inflammation, and oxidant stress in the air spaces of smokers. Am J Respir Crit Care Med 1999; 159: 473-479. 
Mercer BA, Kolesnikova N, Sonett J, et al. Extracellular regulated kinase/mitogen activated protein kinase is upregulated in pulmonary emphysema and mediates matrix metalloproteinase-1 induction by cigarette smoke. J Biol Chem 2004; 279: 17690-17696.

34 Kim H, Liu X, Kohyama T, et al. Cigarette smoke stimulates MMP-1 production by human lung fibroblasts through the ERK1/2 pathway. COPD 2004; 1: 13-23.

35 La Rocca G, Anzalone R, Magno F, et al. Cigarette smoke exposure inhibits extracellular MMP-2 (gelatinase A) activity in human lung fibroblasts. Respir Res 2007; 8: 23.

36 Santus P, Casanova F, Biondi ML, et al. Stromelysin-1 polymorphism as a new potential risk factor in progression of chronic obstructive pulmonary disease. Monaldi Arch Chest Dis 2009; 71: 15-20.

37 Korytina GF, Tselousova OS, Akhmadishinia LZ, et al. [Association of the MMP3, MMP9, ADAM33 and TIMP3 genes polymorphic markers with development and progression of chronic obstructive pulmonary disease]. Mol Biol (Mosk) 2012; 46: 487-499.

38 Gosselink JV, Hayashi S, Elliott WM, et al. Differential expression of tissue repair genes in the pathogenesis of chronic obstructive pulmonary disease. Am J Respir Crit Care Med 2010; 181: 1329-1335.

39 Lopes J, Adiquzel E, Gu S, et al. Type VIII collagen mediates vessel wall remodeling after arterial injury and fibrous cap formation in atherosclerosis. Am J Pathol 2013; 182: 2241-2253.

40 Xu R, Yao ZY, Xin L, et al. NC1 domain of human type VIII collagen (alpha 1) inhibits bovine aortic endothelial cell proliferation and causes cell apoptosis. Biochem Biophys Res Commun 2001; 289: 264-268.

41 Umezawa M, Kudo S, Yanagita S, et al. Maternal exposure to carbon black nanoparticle increases collagen type VIII expression in the kidney of offspring. J Toxicol Sci 2011; 36: 461-468.

42 Yoon $\mathrm{CH}$, Park HJ, Cho YW, et al. Cigarette smoke extract-induced reduction in migration and contraction in normal human bronchial smooth muscle cells. Korean J Physiol Pharmacol 2011; 15: 397-403.

43 Allen-Gipson DS, Zimmerman MC, Zhang H, et al. Smoke extract impairs adenosine wound healing: implications of smoke-generated reactive oxygen species. Am J Respir Cell Mol Biol 2013; 48: 665-673.

44 Miglino N, Roth M, Lardinois D, et al. Cigarette smoke inhibits lung fibroblast proliferation by translational mechanisms. Eur Respir J 2012; 39: 705-711.

45 Oliver BG, Johnston SL, Baraket M, et al. Increased proinflammatory responses from asthmatic human airway smooth muscle cells in response to rhinovirus infection. Respir Res 2006; 7: 71

46 Xie S, Issa R, Sukkar MB, et al. Induction and regulation of matrix metalloproteinase-12 in human airway smooth muscle cells. Respir Res 2005; 6: 148

47 Ito K, Ito M, Elliott WM, et al. Decreased histone deacetylase activity in chronic obstructive pulmonary disease. $N$ Engl J Med 2005; 352: 1967-1976. 